Document downloaded from:

http://hdl.handle.net/10251/98408

This paper must be cited as:

Oscar Carranza Castillo; Garcerá, G.; Figueres Amorós, E.; Luis Gerardo González Morales (2010). Peak current mode control of three-phase boost rectifiers in discontinuous conduction mode for small wind power generators. Applied Energy. 87(8):2728-2736. doi:10.1016/j.apenergy.2010.02.010

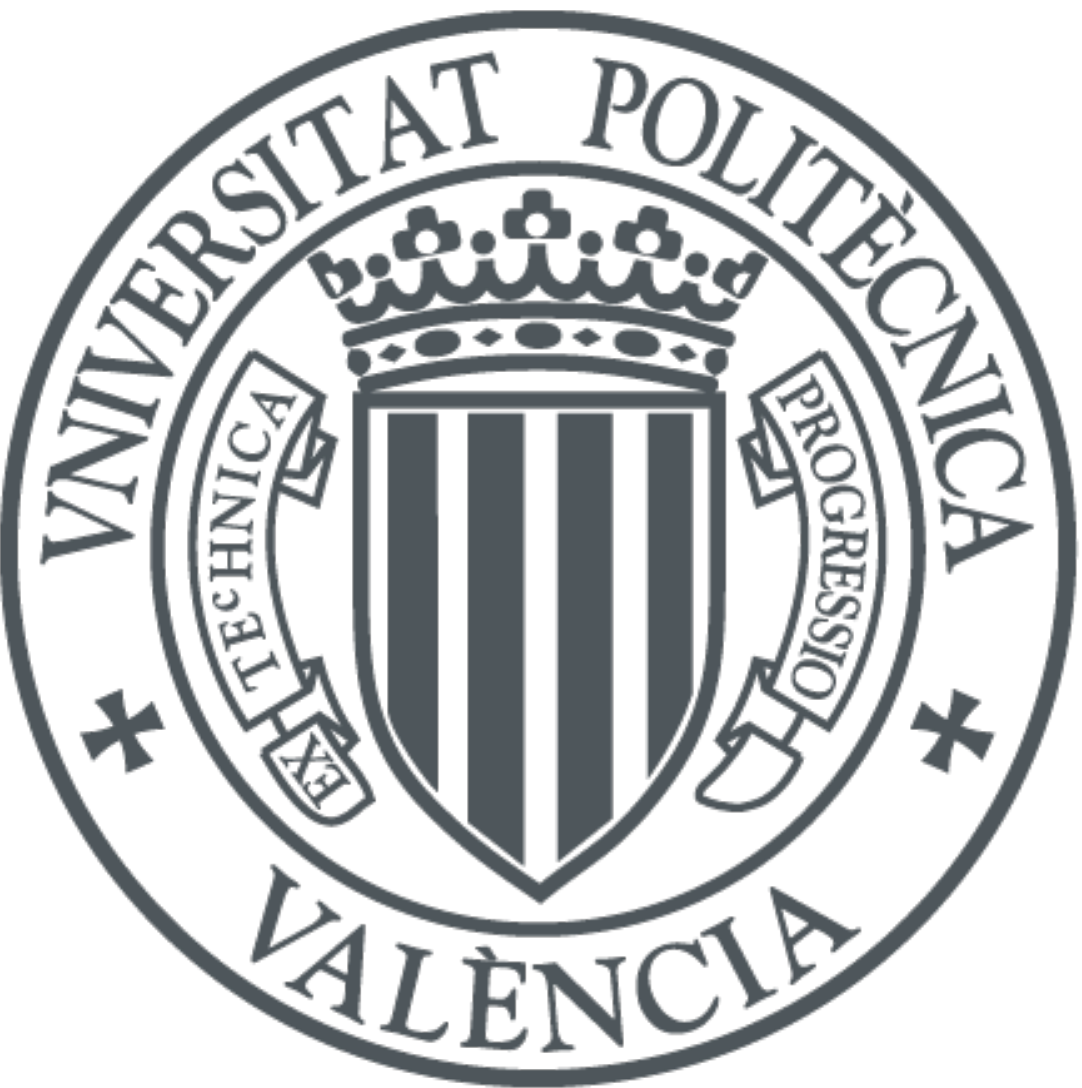

The final publication is available at

https://doi.org/10.1016/j.apenergy.2010.02.010

Copyright Elsevier

Additional Information 


\title{
Peak Current Mode Control of Three-Phase Boost Rectifiers in Discontinuous Conduction Mode for Small Wind Power Generators
}

\author{
O. Carranza ${ }^{1}$, G. Garcerá ${ }^{2}$, E. Figueres ${ }^{2}$, L. G. González ${ }^{3}$ \\ ${ }^{1}$ Escuela Superior de Cómputo, Instituto Politécnico Nacional \\ e-mail: ocarranzac@ipn.mx \\ ${ }^{2}$ Grupo de Sistemas Electrónicos Industriales del Departamento de Ingeniería Electrónica, \\ Universidad Politécnica de Valencia \\ http://www.gsei.upv.es \\ e-mail: ggarcera@eln.upv.es, efiguere@eln.upv.es \\ ${ }^{3}$ Departamento de Ingeniería Electrónica y Comunicaciones, Universidad de los Andes \\ e-mail: Igerardo@ula.ve
}

\begin{abstract}
This paper presents a Peak Current Mode Control scheme of a Boost Rectifier with Low Distortion of the Input Current for Wind Power Systems based on Permanent Magnet Synchronous Generators with variable speed operation. The Three-Phase Boost Rectifier is operated in Discontinuous Conduction Mode (DCM), and power factor correction techniques are applied. It is shown that the DCM operation significantly reduces the Total Harmonic Distortion of the currents in the Permanent Magnet Synchronous Generator, increasing the Power Factor of the system, so that the vibrations and mechanical stress of the generator are minimized. The characteristics of the DCM Boost rectifier are studied considering: 1) The series resistance of the inductors; 2) The modeling and adjustment of peak current mode control yielding a stable loop; 3) The design of an input filter that reduces the switching noise in the currents of the generator.
\end{abstract}

Keywords: Harmonics, Power Factor Correction, Wind generation systems.

\section{Introduction}

Renewable energies for obtaining electric power are currently raising a great interest, mainly due to the high price of fossil fuels and to the need of alternative and clean energy sources. Wind energy is one of these sources [1]-[2], although not all places are capable of taking advantage of it. Nevertheless, several statistical methods have been developed to calculate the average wind speed, the wind power density and its capacity factor for a specific geographical area [3].

Wind energy can be used either as a primary clean energy source that can be combined with conventional energy sources acting as backup, or as a secondary energy source only activated during the peaks of energy demand [4].

Currently, there are numerous projects to implement wind energy farms increasing the production of clean electrical energy [5]. Furthermore, the administrations of many countries are establishing incentives and subsidies for those projects, in order to comply with the Kioto protocol about the reduction of $\mathrm{CO}_{2}$ emissions. This fact makes that wind energy becomes cost-effective, competing with conventional generation of electricity. Several studies analyze the viability of wind energy, regarding both its generation capability to replace fossil energy, and the energy price reduction when introducing wind energy to satisfy the demand [6].

In small power wind generation systems ranging from $1 \mathrm{~kW}$ to $50 \mathrm{~kW}$, permanent magnet synchronous generators (PMSGs) are preferred to other electrical machines like induction generators (IGs) [7]-[8]. The reason of that is the need of IGs to be externally magnetized, so that they may be either directly connected to the grid or indirectly, by means of a back-toback converter. In the first case, the speed regulation is limited up to around a $30 \%$ of the nominal IG speed [7], so that its capability of extracting energy from the wind is reduced. A back to back converter may be used to expand the IG speed range, improving the amount of 
energy that the system can extract from the wind. Nevertheless, this topology is often too complex and expensive to be a good candidate for the low power range. On the contrary, PMSGs don't need an external magnetization, so that they are compatible with the use of passive rectifiers in cost effective grid decoupled systems. In addition, the use of a gearbox may be avoided, simplifying the mechanical structure of the system. PMSGs can work in grid isolated geographical zones and in a wide wind speed range, extracting a higher energy from the wind [8]-[9] than IGs.

Due to the fact that both the output voltage and the frequency of a PMSG depend on the wind speed, an electronic converter is required for connecting the generator to the grid. The simplest electronic converter is constituted by a non-controlled three phase rectifier with capacitive filter followed by a grid connected inverter. The drawback of this option is that the DC-link voltage may be too low for injecting to the grid, so that a high turns-ratio step-up grid connection transformer is necessary. Therefore, the inverter currents are high and, consequently, the inverter losses. Both the grid connection transformer and the grid filter (usually LCL) become bulky because of the high inverter side current.

If a higher efficiency and a lower size are desired, a Boost DC-DC converter is usually connected between the rectifier and the inverter, achieving a higher inverter DC-link voltage, so that the grid connection transformer has a smaller turns-ratio, and thus lower inverter currents. Fig. 1 shows a wind generation system based on a non-controlled three phase rectifier followed by a Boost DC-DC converter, also called Boost Rectifier, connected to the grid by means of a PWM inverter. In this case, the output voltage of the boost rectifier is regulated to a constant value, $V_{o}$, by the control loops of the inverter. The control of the rectifier adjusts the duty cycle of the boost active switch (an IGBT in Fig. 1) to obtain the maximum available power from the PMSG.

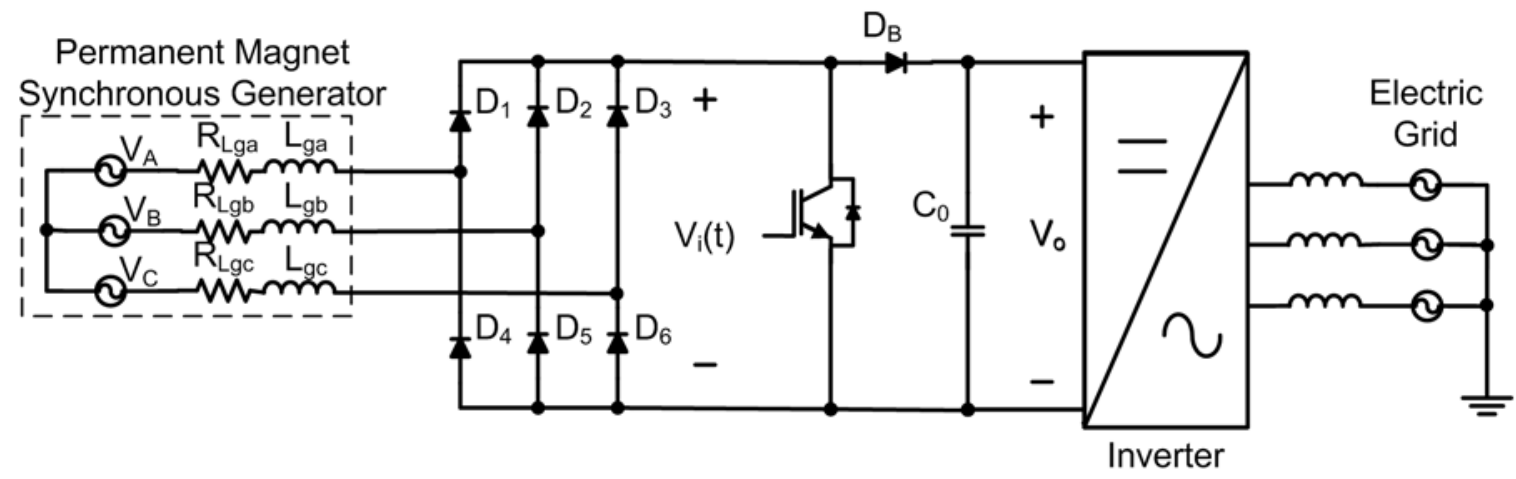

Fig. 1. Wind energy generation system based on a Three-Phase Boost Rectifier.

If the Boost Rectifier operates in Continuous Conduction Mode (CCM), the wind power generator current has a high Total Harmonic Distortion $\left(T H D_{i}\right)$, resulting in a low Power Factor (PF) [10]-[12]. A further drawback of this kind of wind energy conversion systems (WECS) is their low reliability and efficiency, specially if switching frequencies higher than $10 \mathrm{kHz}$ are used [13].

Besides, a high $\mathrm{THD}_{i}$ produces overheating and torque vibrations in the generator, which increase the mechanical stress and maintenance. Fig. 2 shows the $\mathrm{THD}_{i}$ and the PF of a sample $2 \mathrm{~kW}$ PMSG driven by a three-phase diode rectifier and a Boost DC-DC converter (Boost rectifier) in CCM. The permanent magnet synchronous generator (PMSG) characteristics are described in Table I. The sample waveforms in Fig. 2 correspond to the current and voltage at one of the phases of the PMSG under the following conditions: $n_{m}=$ $450 \mathrm{rpm}$ and $P=2 \mathrm{~kW}$. The generator torque waveform has been also represented. 

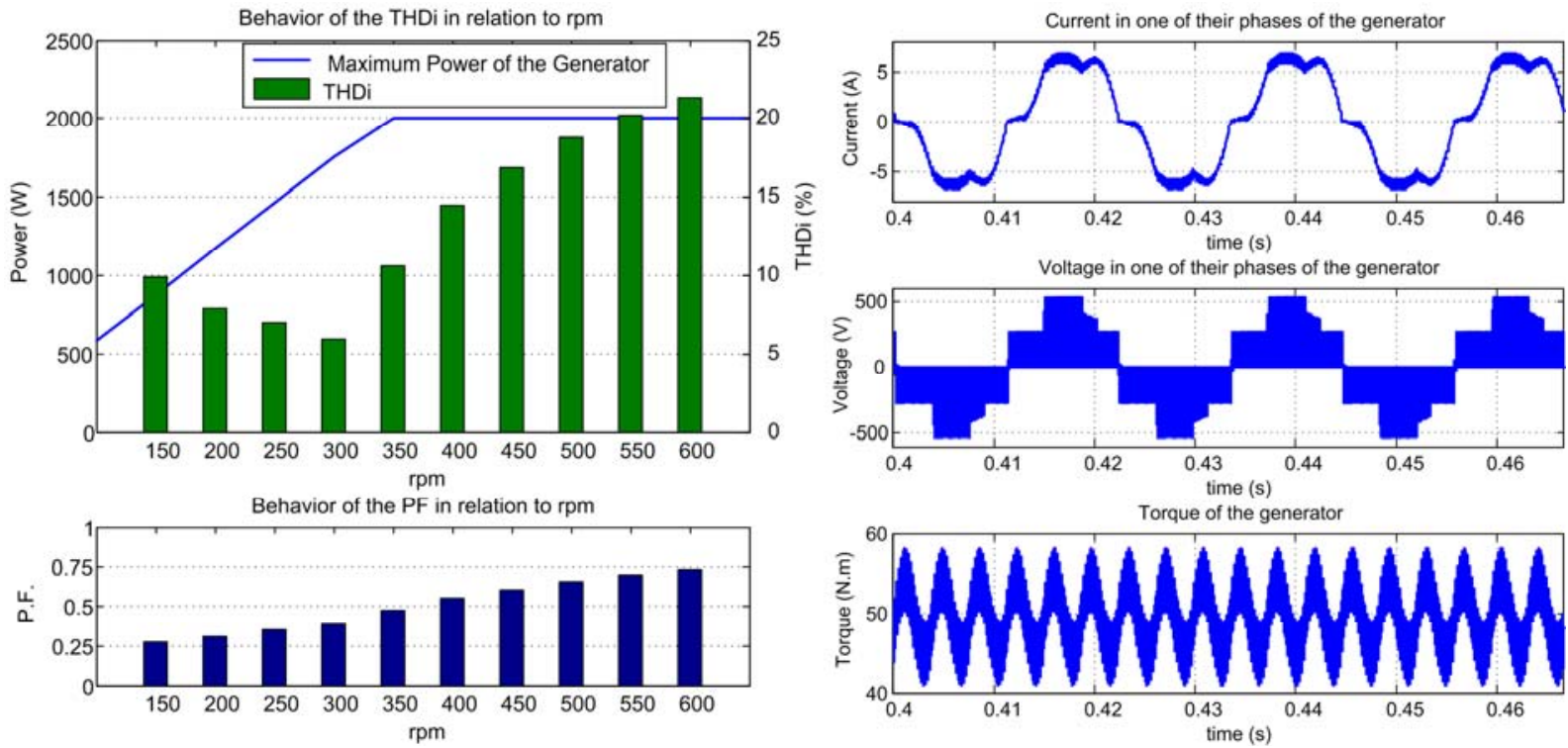

Fig. 2. Behavior of the THDi and the PF of a PMSG driven by a Boost Rectifier in CCM. Torque, phase current and phase voltage waveforms at $2 \mathrm{~kW}$ and $450 \mathrm{rpm}$.

In Fig. 2 it can be observed that a very low power factor results, ranging from 0.27 to 0.74 . The PF is particularly poor for low values of the PMSG speed (expressed in rpm). This issue implies that the Boost rectifier in CCM is highly inefficient to extract the maximum available power from the wind, particularly at low wind speeds. Furthermore, a high $T H D_{i}$ of the generator current is observed from Fig. 1, ranging from $6 \%$ to $22 \%$. Besides, the torque waveform has a ripple of $17.17 \mathrm{Nm}$ (34.66 \% of its average value), containing both low and switching frequency harmonics. This ripple produces an undesired mechanical stress in the PMSG, reducing its life cycle.

The described negative features give rise to the study of new solutions for improving the energetic efficiency of small WECSs [13].

If the Boost Rectifier operates in Discontinuous Conduction Mode (DCM) and a power factor correction technique is applied, the Boost Rectifier is useful to reduce the $T H D_{i}$ and to increase the PF of the wind power generator. This operation mode has been proposed in [14]-[17] to reduce the $\mathrm{THD}_{\mathrm{i}}$ in switch-mode power supplies. Besides, it is necessary to design an input filter between the generator and the rectifier in order to achieve DCM operation of the rectifier.

In the proposed WECS the grid connected inverter regulates both the DC-link voltage (i.e. the output of the Boost rectifier) and the grid currents. Therefore, the inverter may be 'seen' by the boost rectifier as a DC voltage as a first approximation.

An remarkable contribution of this work with respect to [14]-[17] is that both the amplitude and the frequency of the generator output voltage are variable with the wind speed, so that it is necessary to carefully design both the power stage and the control loop.

This paper is focused on the analysis and design of the current control loop of the system, which allows regulating the PMSG electrical torque. Fig. 3 depicts the concept of torque vs. speed control of a WECS based on a Boost rectifier. The proposed technique is compatible with both speed and torque control structures [18], whose study are out of the scope of this paper. The block MPPT stands for the Maximum Power Point algorithm that provides the reference current, $I_{\text {ref, }}$ in the torque (current) control structure, or the speed reference, $\omega_{\text {ref, }}$ in the speed control structure. Note that in both structures a current control is necessary. 
Permanent Magnet Synchronous Generator

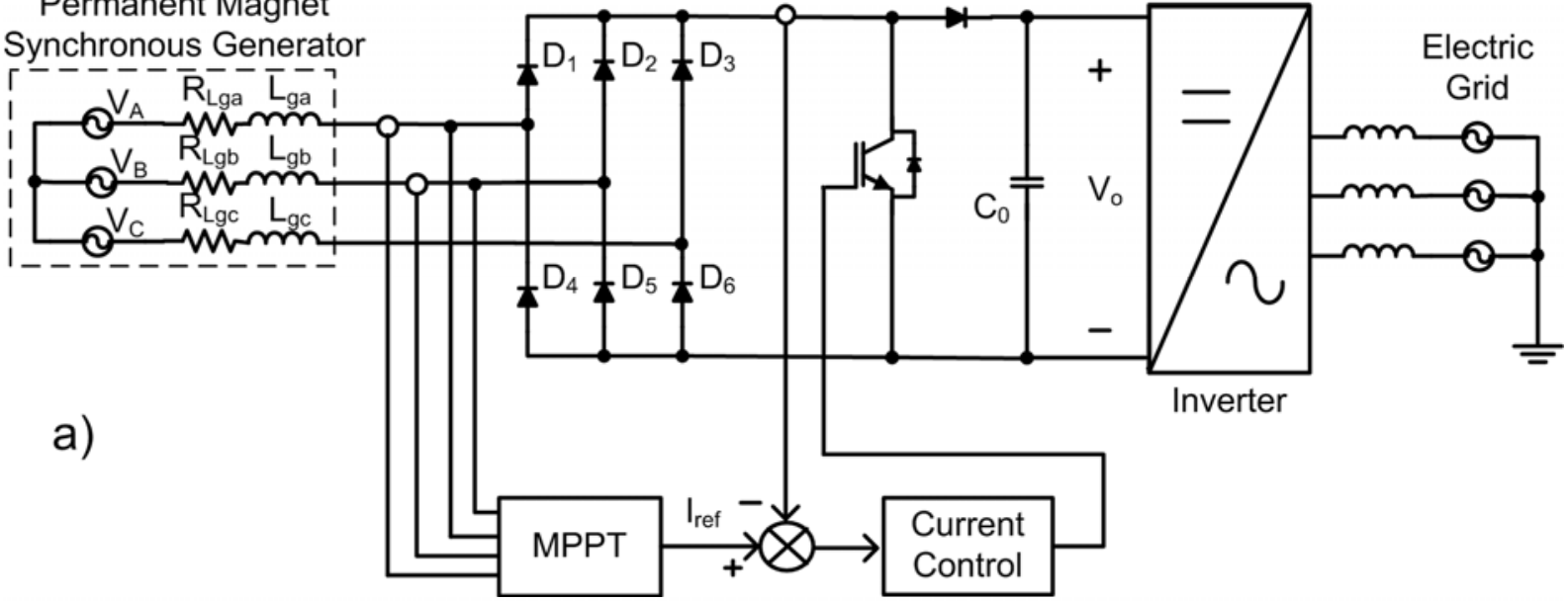

Permanent Magnet Synchronous Generator

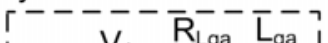

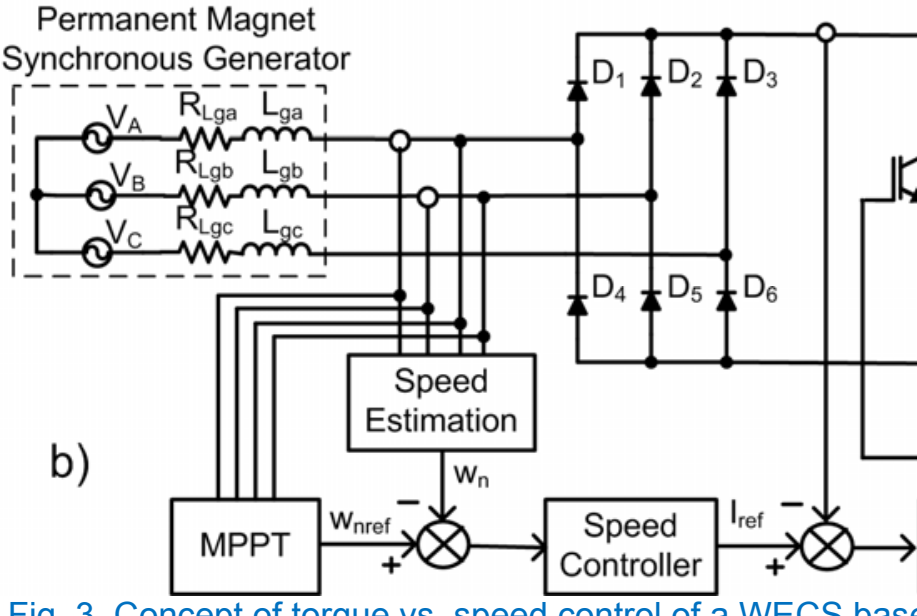

$D_{B}$

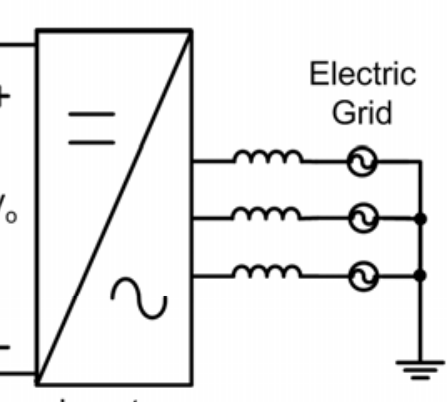

Fig. 3. Concept of torque vs. speed control of a WECS based on a Boost rectifier. a) Torque (current) control structure. b) Speed control structure.

\section{Boost Rectifier in DCM}

Fig. 4 shows the scheme of the proposed DCM Three-Phase Boost Rectifier with input filter under study, whereas Table I shows the values of the PMSG used in the proposed WECS.

Table I: Characteristics of the PMSG in the proposed WECS.

\begin{tabular}{lc}
\hline \multicolumn{1}{c}{ Characteristics } & Values \\
\hline Maximum output power of the generator $(P)$ & $2 \mathrm{~kW}$ \\
Output voltage range of the generator $\left(V_{a b}\right)$ & $104-416 \mathrm{~V}_{\text {rms }}$ \\
Inductance of one phase of the generator $\left(L_{g a}, L_{g b}, L_{g c}\right)$ & $25 \mathrm{mH}$ \\
Resistance of one phase of the generator $\left(R_{g a}, R_{g b}, R_{g c}\right)$ & $5 \Omega$ \\
Electromotive force constant $\left(K_{\text {emf }}\right)$ & $6.63 \mathrm{~V}_{\mathrm{rms}} / \mathrm{rad} / \mathrm{s}$ \\
Number of poles $\left(n_{p}\right)$ & 12 \\
Nominal Current $\left(I_{\text {nom }}\right)$ & $4.87 \mathrm{~A}_{\mathrm{rms}}$ \\
Speed Range of the generator $\left(n_{m}\right)$ & $150-600 \mathrm{rpm}$ \\
Average voltage at the output of the diode bridge $\left(V_{i}\right)$ & $141-563 \mathrm{~V}$ \\
Output Voltage of the Boost rectifier $\left(V_{o}\right)$ & $800 \mathrm{~V}$ \\
Boost rectifier switching frequency $\left(f_{s}, f_{s}=1 / T_{s}\right)$ & $5 \mathrm{kHz}$ \\
\hline
\end{tabular}


The circuit used for the analysis considers two phases of the PMSG, during the time interval when 2 diodes of the non-controlled rectifier are conducting; the circuit is reduced to that shown in Fig. 5.

It is considered that $L_{g}=2 L_{g a}, R_{g}=R_{g a}, L=2 L_{a}, R_{L}=2 R_{L a}$ and $C_{i}=3 C_{f} / 2 . V_{i}$ is the average value of the Boost DC-DC converter input voltage, i.e., the average output voltage of the three-phase diode bridge rectifier. The voltage drops in the rectifier diodes and inductors resistances have been neglected. The equivalent $\mathrm{DC}$ voltage $V_{i}$ is determined by (1).

$$
V_{i}=\frac{\sqrt{2} K_{e m f} n_{m}}{10}
$$

The equivalent circuit is shown in Fig. 6 . The boost rectifier output voltage, $V_{o}$, is regulated by the grid connected inverter to a constant value of $800 \mathrm{~V}$.

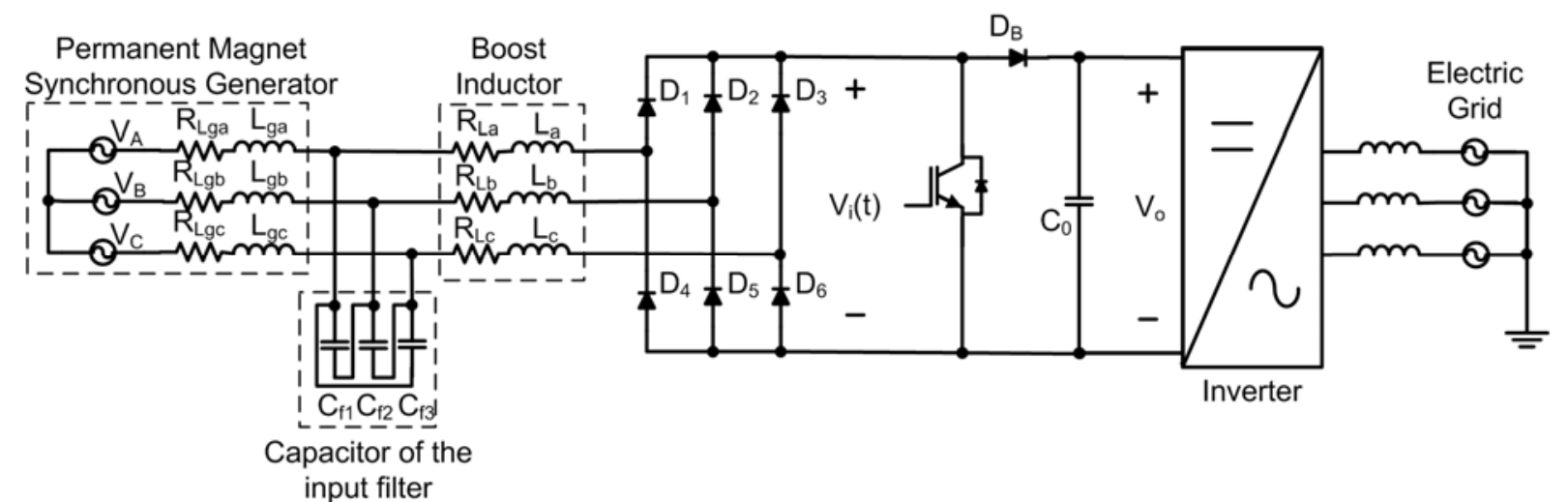

Fig. 4. DCM Three-Phase Boost Rectifier with input filter.

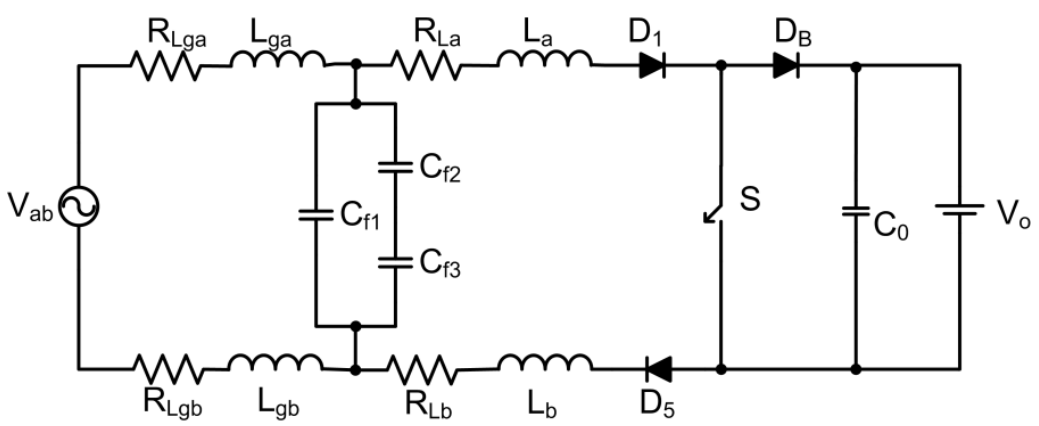

Fig. 5. Circuit of the Boost Rectifier when diodes $D_{1}$ and $D_{5}$ are conducting.

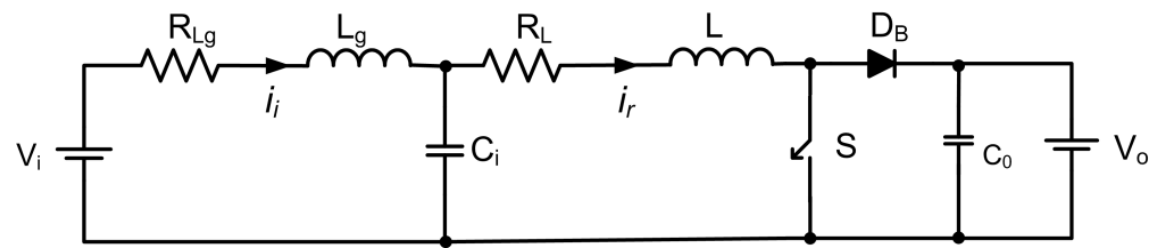

Fig. 6. Equivalent Circuit of the Boost Rectifier with input filter.

\subsection{Operation in Discontinuous Conduction Mode}

In order to work in discontinuous conduction mode (DCM) [18], condition (2) should be met. This condition allows calculating the correct value of $L$. In (2) $D$ is the duty cycle; $L$ is the 
equivalent Boost inductance, $K_{\text {crit }}$ allows to determine the conduction mode of the Boost, and $f_{S}$ is the switching frequency.

$$
\begin{gathered}
K=\frac{2 L P f_{s}}{V_{0}^{2}} \text { and } K_{c r i t}(D)=D(1-D)^{2} \\
K<K_{\text {crit }}(D) \text { for } \mathrm{DCM}
\end{gathered}
$$

The duty cycle in DCM is obtained from (3)

$$
D=\frac{\left(2 V_{0}-V_{i}\right)+V_{i} \sqrt{1+\frac{8 V_{0} L f_{S}}{R_{L}^{2} P}\left(V_{0}-V_{i}\right)}}{V_{0}\left(\frac{2 V_{i}^{2}}{P R_{L}}-\frac{R_{L}}{L f_{S}}\right)}
$$

The condition to work in DCM is obtained by from (2) is expressed by (4)

$$
\frac{2 L P f_{s}}{V_{0}^{2}}<D(1-D)^{2}
$$

The maximum value of the Boost inductance to work in DCM $\left(L_{\max }\right)$ is obtained from (4)

$$
L_{\max }<\frac{D V_{0}^{2}(1-D)^{2}}{2 P f_{s}}
$$

Substitution of (3) into (5) leads to

$$
L_{\max }<\frac{V_{i}^{2}\left(V_{0}-V_{i}\right)+P R_{L}(3 V i-2 V o)+\left[P R_{L}+V_{i}\left(V_{0}-V_{i}\right)\right] \sqrt{V_{i}^{2}-4 P R_{L}}}{2 P f_{s} V_{0}}
$$

, where $V_{i}$ is given by (1)

Fig. 7 shows the value of $L_{\max }$ as a function of the PMSG speed for various values of the generated power. 


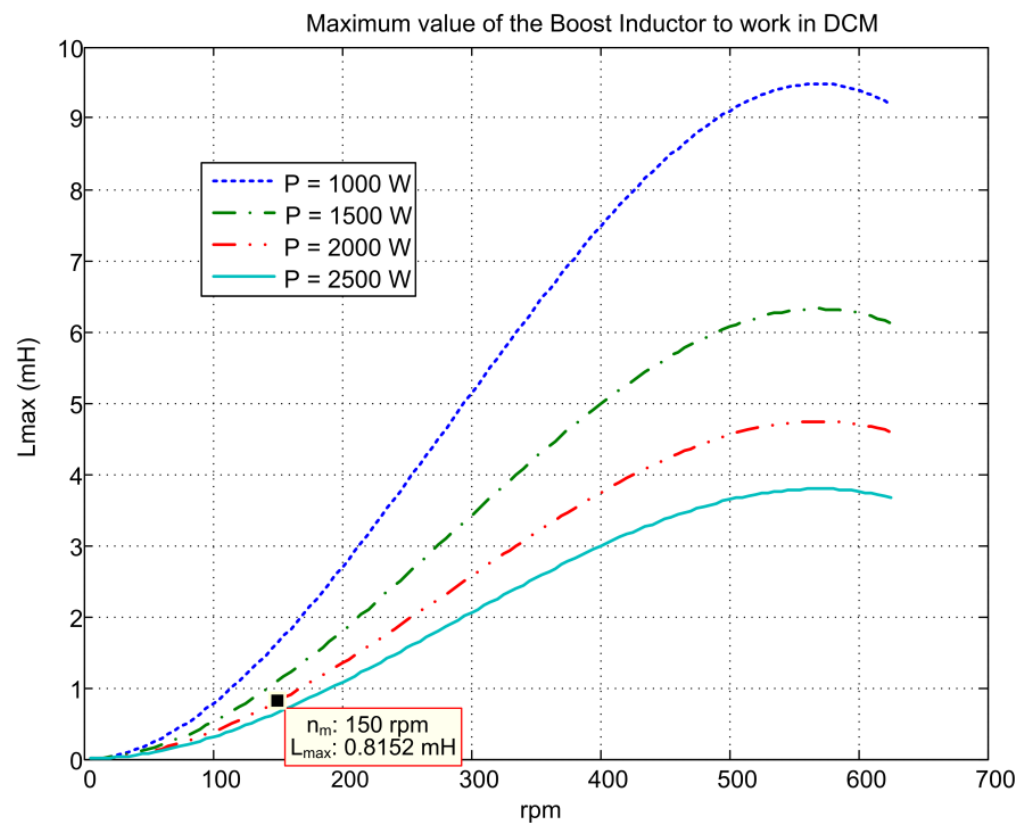

Fig. 7. Value of $L_{\max }$ as a function of the PMSG speed for various values of the generated power.

Considering the whole generator speed range and $P=2 \mathrm{~kW}$, it results: $L_{\max }=815.2 \mu \mathrm{H} . \mathrm{L}=$ $750 \mu \mathrm{H}$ is selected, so that the Boost rectifier operates in DCM in the whole operation range.

\subsection{Input filter design.}

In order to reduce the switching frequency harmonics of the rectifier input current, an LCL input filter is applied. The input filter is designed to attenuate the switching frequency without affecting the frequencies corresponding to the speed range of the generator. Fig. 8 shows the equivalent circuit considering that the switching frequency component of $V_{i}$ is null.

The transfer function from the rectifier current, $I_{r}(\mathrm{~s})$, to the generator current, $I_{i}(\mathrm{~s})$, is determined by (7).

$$
\frac{I_{i}(s)}{I_{r}(s)}=\frac{1}{s^{2} C_{i} L_{g}+s C_{i} R_{L g}+1}
$$

With $C_{i}=3.3 \mu \mathrm{F}$ an attenuation of $-44.3 \mathrm{~dB}$ at the switching frequency $\left(f_{s}=5 \mathrm{kHz}\right)$ is obtained, without affecting the generator frequency range $\left(f_{\text {gen }} \leq 65 \mathrm{~Hz}\right)$. The Bode diagram of the filter is shown in Fig. 9.

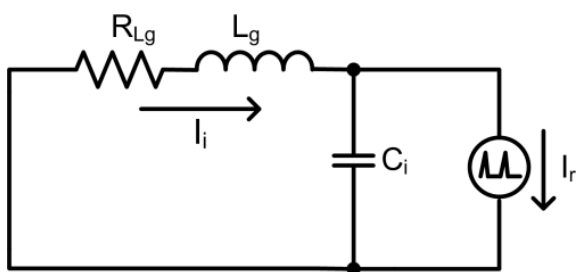

Fig. 8. Equivalent Circuit of the Boost Rectifier with input filter. 


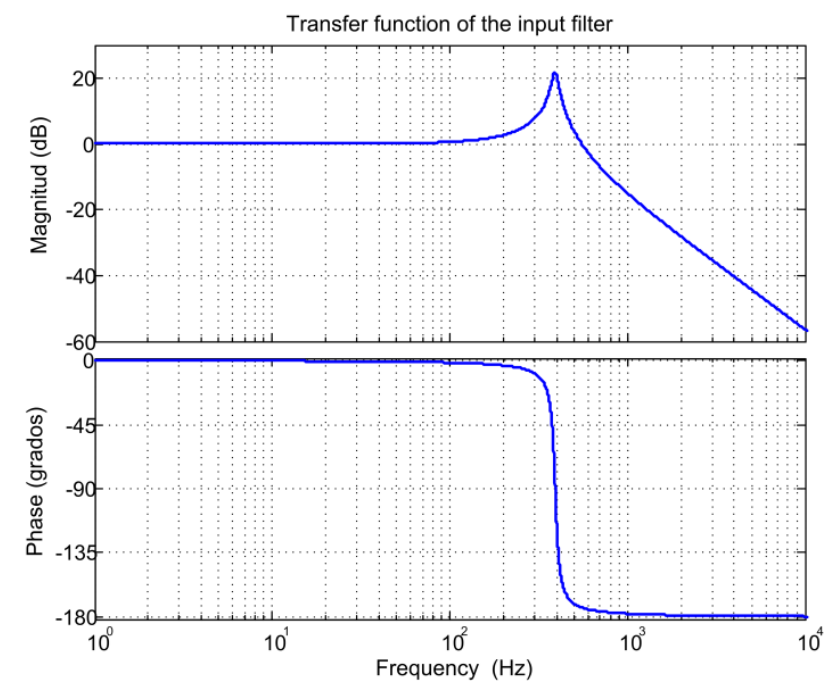

Fig. 9. Bode Diagram of the Input Filter Transfer Function $I_{i}(s) / I_{r}(s)$.

\section{Peak Current Mode Control}

\subsection{Small Signal Model of the Boost Rectifier in DCM}

The small-signal circuit of the Boost rectifier in DCM uses the equivalent circuit of the PWM switch [20], shown in Fig. 10. This model is valid from DC up to $f_{s} / 2$. The rectifier output voltage $\left(V_{0}\right)$ is regulated by the grid connected inverter. Therefore, the load of the Boost rectifier may be modeled as an ideal voltage source.

The values of the parameters of the PWM switch small-signal model in DCM are shown in (8).

$$
\begin{gathered}
g_{i}=\frac{D^{2}}{2 L f_{s}} \quad g_{o}=\frac{2 L P_{o}^{2} f_{s}}{D^{2} V_{i}^{2} V_{o}^{2}} \quad g_{f}=\frac{2 P_{o}}{V_{i} V_{o}} \\
K_{i}=-\frac{D V_{i}}{L f_{s}} \quad K_{o}=-\frac{2 P_{o}}{D V_{o}}
\end{gathered}
$$

$G_{i d}(s)=\hat{\imath}_{L}(s) / \hat{d}(s)$ is the transfer function from the duty cycle to the inductor current, expressed by (9). Fig. 11 shows the Bode plot of $G_{i d}$ for various values of the generator speed, $n_{m}$.

$$
\begin{gathered}
G_{i d}(s)=\frac{\hat{\imath}_{L}(s)}{\hat{d}(s)}=\frac{-\left(s^{2} C_{i} L_{g}+s C_{i} R_{g}+1\right)\left(K_{i}+K_{o}\right)}{s^{3} B_{3}+s^{2} B_{2}+s B_{1}+B_{0}} \\
B_{3}=C_{i} L_{g} L\left(g_{i}+g_{o}+g_{f}\right) \\
B_{2}=C_{i}\left[L_{g}+\left(g_{i}+g_{o}+g_{f}\right)\left(L R_{L_{g}}+L_{g} R_{L}\right)\right] \\
B_{1}=\left[C_{i} R_{L_{g}}+\left(g_{i}+g_{o}+g_{f}\right)\left(L_{g}+L+C_{i} R_{L} R_{L_{g}}\right)\right] \\
B_{0}=\left(g_{i}+g_{o}+g_{f}\right)\left(R_{L_{g}}+R_{L}\right)+1
\end{gathered}
$$

\subsection{Peak Current-Mode Controller}


The structure of the peak current-mode control (PCC) [21] of this converter is shown in Fig. 12. As it has been previously commented, the output voltage $\left(V_{o}\right)$ of the Boost rectifier is regulated by the grid-connected inverter. In a torque control structure an MPPT algorithm would directly provide the value of the control voltage, $V_{C}$, to the current loop. In a speed control scheme the control voltage would be provided by the speed controller, see Fig. 3. PCC is compatible with both control structures. Note that signal $V_{C}$ of PCC is equivalent to signal $I_{\text {ref }}$ in Fig. 3 . The calculation of $V_{C}$ is beyond the scope of the present study.

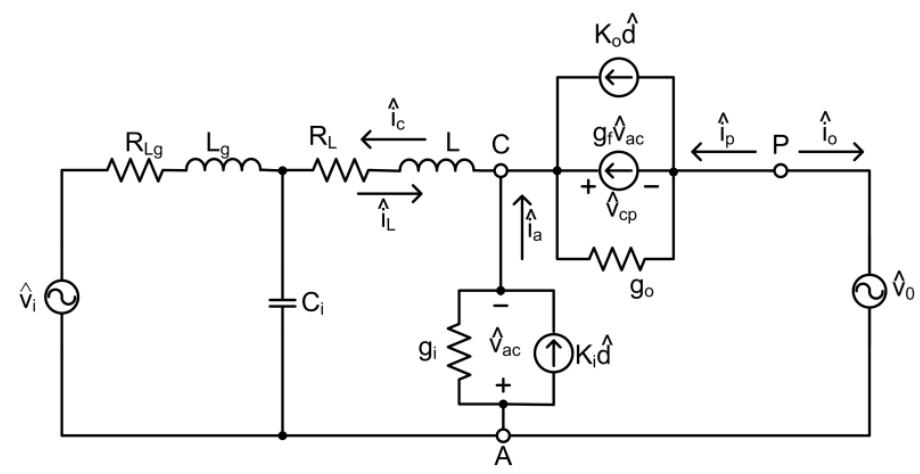

Fig. 10. Small Signal Equivalent Circuit of the Boost Rectifier in DCM with a constant voltage source at the output.

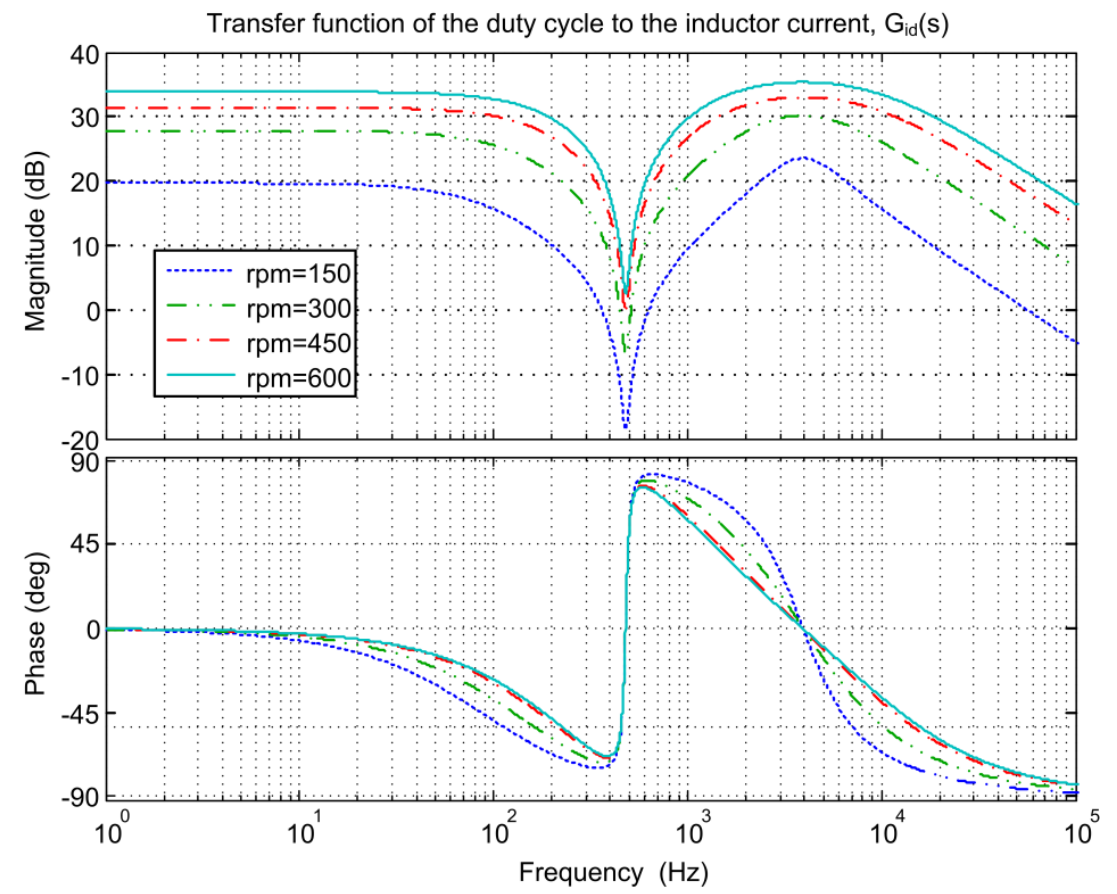

Fig. 11. Transfer Function from the duty cycle to the inductor current, $G_{i d}(s)=\hat{\imath}_{L}(s) / \widehat{d}(s)$, in the generator speed range.

The loop gain of the current loop, $T_{i}(s)$, is determined by (10). $R_{i}$ is the current sense gain, $F_{M}$ is the PWM modulator gain, and $H_{e}(s)$ is the sampling gain [21], typical in peak current mode control.

$$
T_{i}(s)=G_{i d}(s) H_{e}(s) R_{i} F_{M}
$$

The sampling gain $H_{e}(s)$ is expressed by (11) 


$$
H_{e}(s)=1+\frac{s}{\omega_{z} Q_{z}}+\frac{s^{2}}{\omega_{z}^{2}}
$$

, where

$$
\begin{gathered}
\omega_{z}=\frac{\pi}{T_{s}}=\frac{\pi}{200 \mu \mathrm{s}}=15707.963 \frac{\mathrm{rad}}{\mathrm{s}} \\
Q_{z}=-\frac{2}{\pi}=-0.6366
\end{gathered}
$$

In order to guarantee the stability of the current loop, $F_{M}$, expressed by (12), should be adjusted properly.

$$
\begin{gathered}
F_{M}=\frac{f_{s}}{\left(S_{n}+S_{e}\right) T_{s}}=\frac{f_{s}}{m_{c} S_{n}} \\
m_{c}=1+\frac{S_{e}}{S_{n}}
\end{gathered}
$$

In (12) $S_{n}$ is the on-time slope of the current sense waveform, $S_{e}$ is the slope of the stabilization ramp and $m_{c}$ is the modulation index. The value of $S_{n}$ is obtained from (13).

$$
s_{n} \approx \frac{V_{i}}{L} R_{i}
$$

Taking into account the values chosen for $L=750 \mu \mathrm{H}$, and $R_{i}=0.01 \Omega$, the worst stability case takes place at the maximum generator speed, $n_{m \_ \text {max }}=600 \mathrm{rpm}\left(V_{i_{-} \max } \approx 563 \mathrm{~V}\right), P=2$ $\mathrm{kW}$. These values yield: $S_{n}=7.501 \mathrm{~V} / \mathrm{ms}$. The value of $m_{c}$ is chosen so that the current loop becomes as stable as possible. Fig. 13 shows the Bode Diagram of the transfer function from the control voltage to the inductor current, $G_{i c}(s)=\hat{\imath}_{L}(s) / \widehat{v}_{c}(s)$, for values of $m_{c}$ between 2 and 5 , at the worst stability case.

In Fig. 13 it is observed that for $m_{c}=2$ and $m_{c}=3$ the current loop is unstable because the phase of the closed loop transfer function, $G_{i c}(s)$, undergoes a positive phase transition corresponding to complex conjugated high frequency poles. This means that the closed loop poles of the current loop are located in the complex right half plane, yielding an unstable current loop. With $m_{c} \geq 4$, it is observed that the control loop is stable because the phase transition of $G_{i c}(s)$ is negative. The value of $S_{e}$ has been designed for obtaning $m_{c}=4$ in the worst stability case. The resulting value is $S_{e}=22.503 \mathrm{~V} / \mathrm{ms}$. 


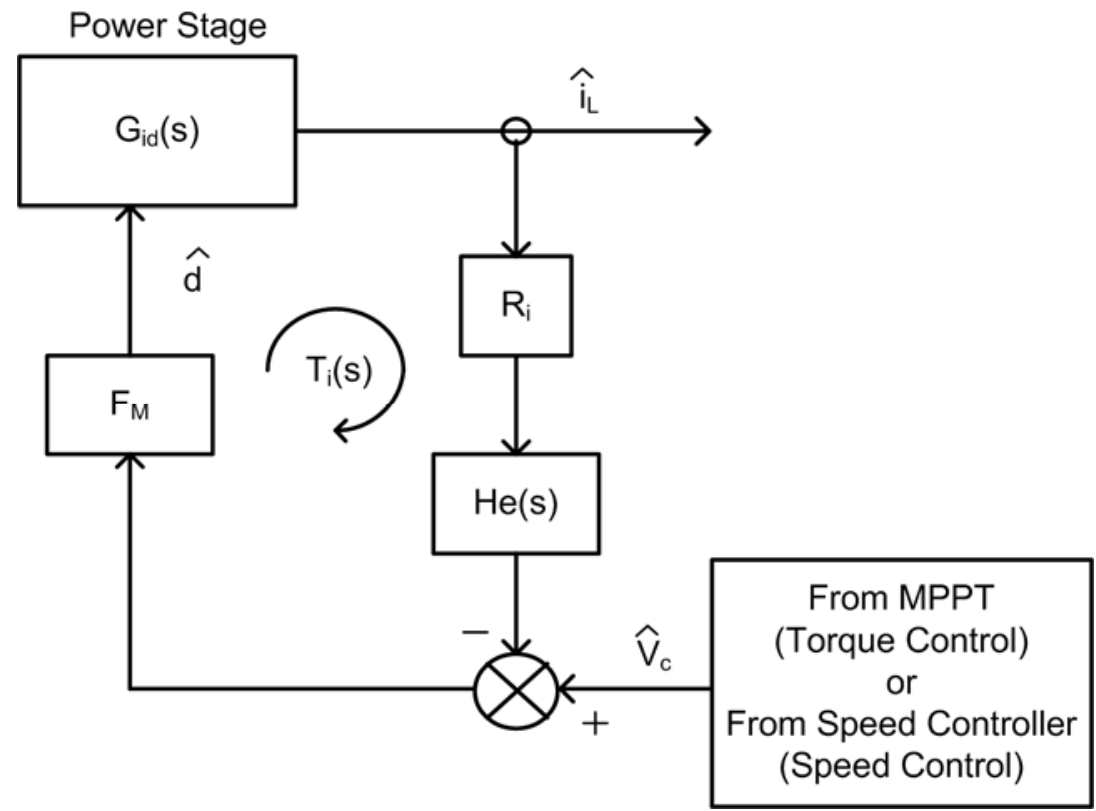

Fig. 12. Peak Current-Mode Control Loop.

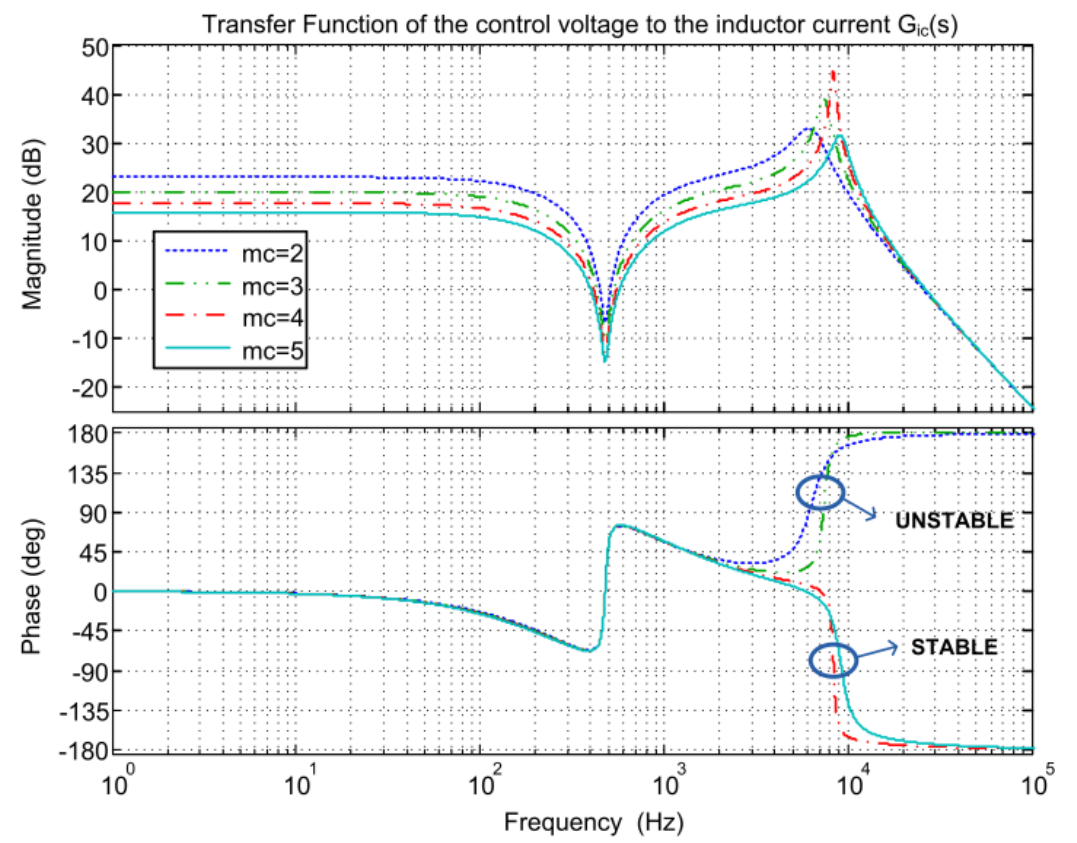

Fig. 13. Transfer Function of the control voltage to the inductor current, $G_{i c}(s)=\hat{\imath}_{L}(s) / \widehat{v}_{c}(s)$, with $m_{c}$ variation at the worst stability case: $n_{m \_ \text {max }}=600 \mathrm{rpm}, V_{i \_ \text {max }} \approx 563 \mathrm{~V}, P=2 \mathrm{~kW}$.

In Fig. 14 it is observed that with $S_{e}=22.503 \mathrm{~V} / \mathrm{ms}$ and between $150 \mathrm{rpm}$ and $600 \mathrm{rpm}$ the current loop is stable because the phase transition of $G_{i c}(s)$ is negative. 


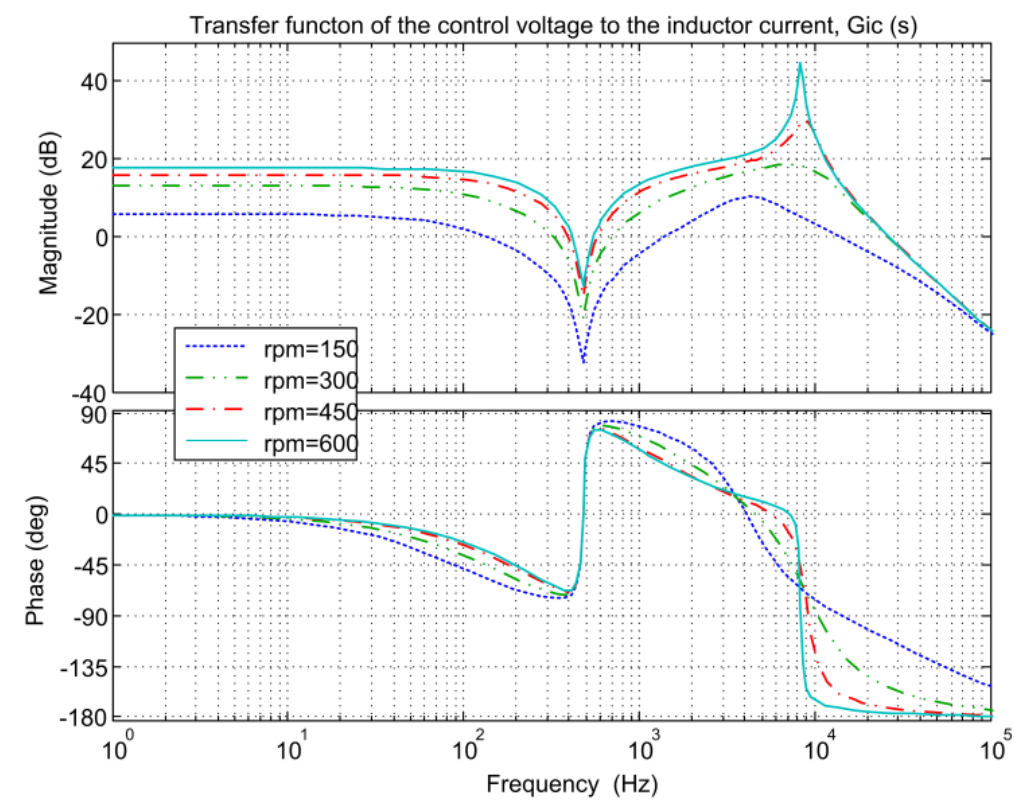

Fig. 14. Transfer Function of the control voltage to inductor current, $G_{i c}(s)=\hat{\imath}_{L}(s) / \widehat{v}_{c}(s)$ as a function of the generator speed for $S_{e}=22.503 \mathrm{~V} / \mathrm{ms}$.

\section{Results}

After the design of the input filter and of the PCC control, the behavior of the system has been simulated by means of PSIM ${ }^{\mathrm{TM}}$ [22] software. The complete circuit is shown in Fig. 15, where a speed control scheme has been depicted. Table II shows the values of the input filter and of the PCC loop. The electrical parameters of the PMSG have been shown in Table I. The value of the control voltage, $V_{C}$, for the peak current mode controller is provided by an MPPT algorithm, designed to obtain the maximum power from the PMSG. The study of the MPPT algorithm, the speed estimation and the speed controller are beyond the scope of this paper.

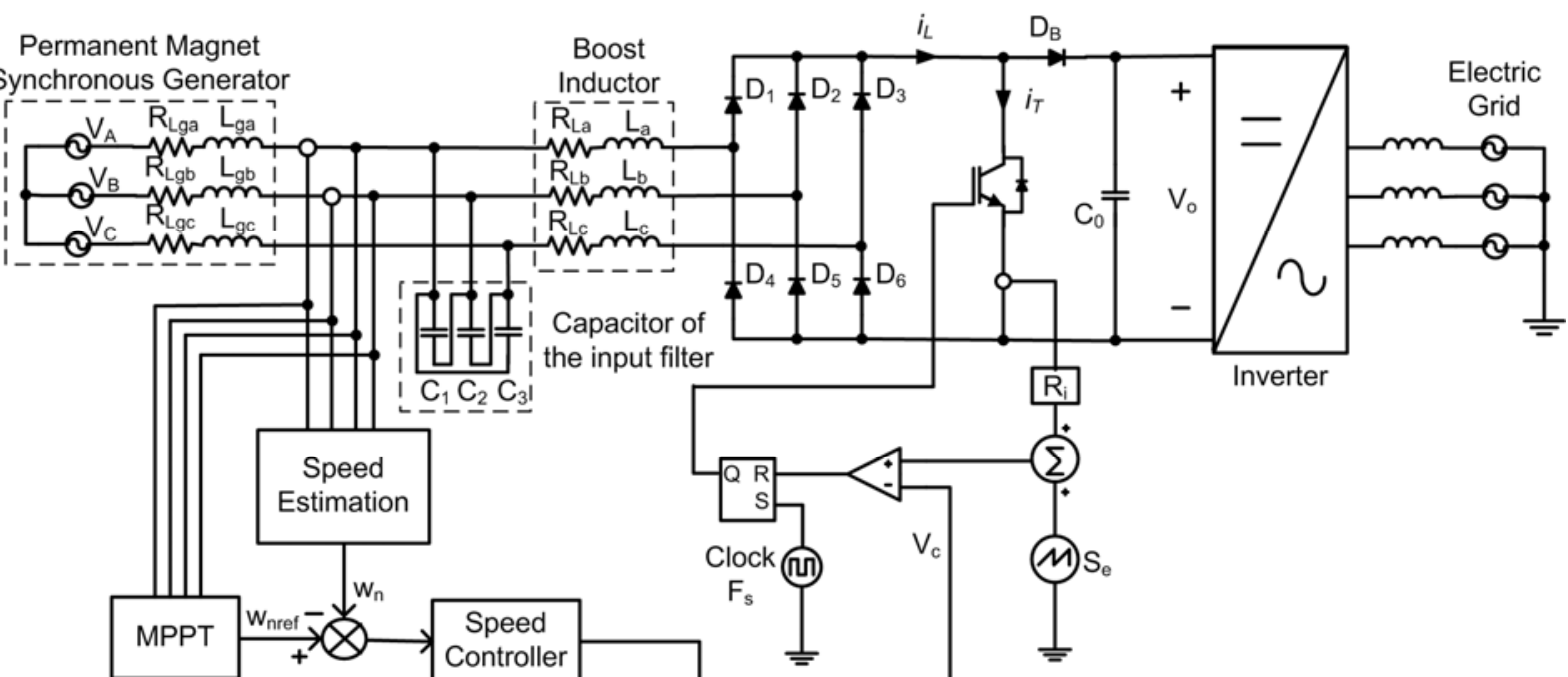

Fig. 15. Speed control structure of the Three Phase Boost Rectifier in DCM with input filter and PCC Control.

Table II: Values of the input filter and of the PCC loop.

$$
\text { Characteristics }
$$




\begin{tabular}{lc}
\hline Resistance in series associated to the Boost inductor in each & $\approx 100 \mathrm{~m} \Omega$. \\
phase $\left(R_{L a}, R_{L b}, R_{L c}\right)$ & $2.2 \mu \mathrm{F}$ \\
Capacitance of the filter $\left(C_{f 1}, C_{f 2}, C_{f 3}\right)$ & $0.01 \Omega$. \\
Current sense gain $\left(R_{i}\right)$ & $22.5 \mathrm{~V} / \mathrm{ms}$ \\
Slope of the stabilization ramp $\left(S_{e}\right)$ & $5 \mathrm{kHz}$ \\
Boost rectifier switching frequency $\left(f_{s}\right)$ & $800 \mathrm{~V}$ \\
Output Voltage of the Boost rectifier $\left(V_{o}\right)$ & \\
\hline
\end{tabular}

Fig. 16 a) shows the current in one of the generator phases of the Boost Rectifier working in CCM in comparison with the same current of the proposed DCM Boost rectifier with the designed PCC and input filter. In both cases the operation point of the PMSG is $n_{m}=450$ $\mathrm{rpm}$ and $P=2 \mathrm{~kW}$. It is observed that the proposed rectifier reduces both the low frequency and the switching harmonics. The reduction of high frequency harmonics in the currents drawn from the PMSG is achieved by the input filter of the proposed rectifier. That feature is important for mitigation of EMI problems.

Fig. $16 \mathrm{~b}$ ) shows the torque at the PMSG with both rectifiers at $n_{m}=450 \mathrm{rpm}$ and $P=2 \mathrm{~kW}$. It is observed that the proposed rectifier decreases the torque ripple from $17.2 \mathrm{Nm}(34.7 \%$ of the average torque) to $6.6 \mathrm{Nm}(13.7 \%$ of the average torque). It can be concluded that the proposed rectifier achieves an important reduction of the PMSG mechanical stress.
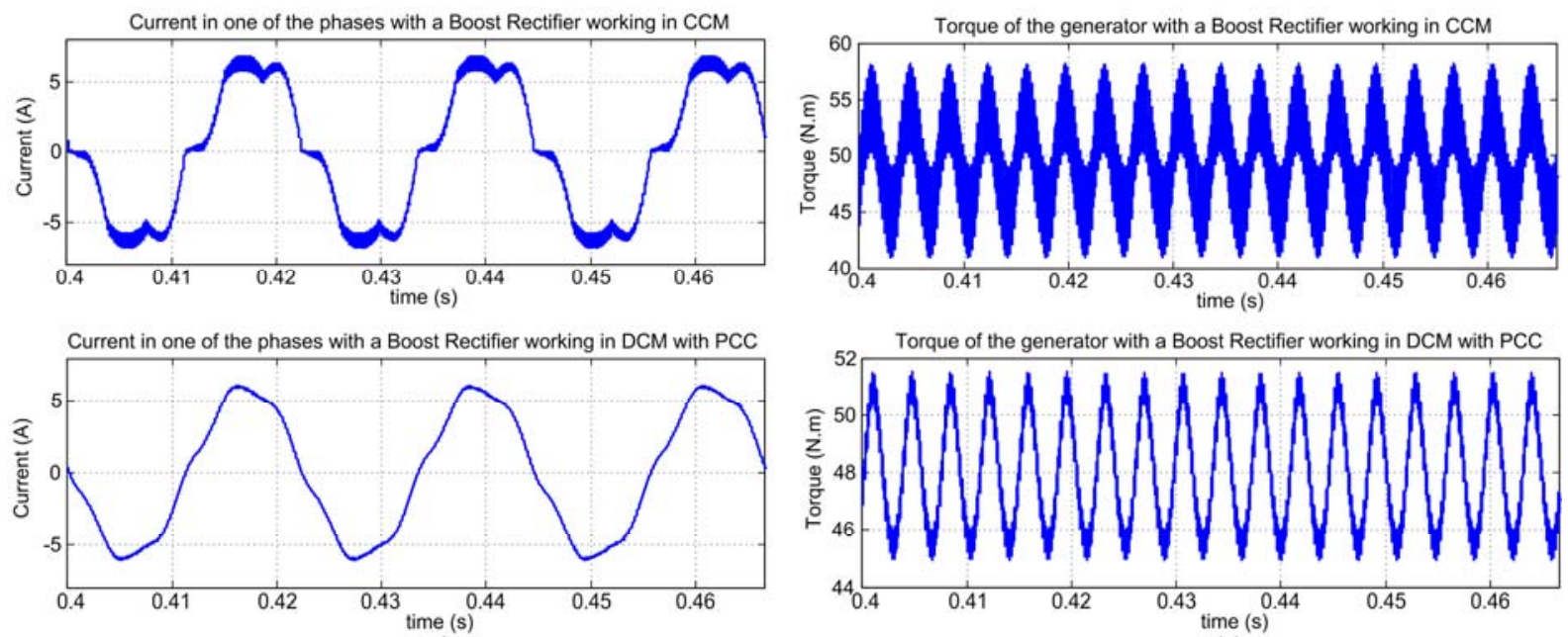

a)

b)

Fig. 16. Generator phase current of a Boost rectifier working in CCM vs. DCM with input filter: $n_{m}=$ $450 \mathrm{rpm}, P=2 \mathrm{~kW}$. a) Currents in one phase of the PMSG, b) Torque at the PMSG.

Fig. 17 shows the low frequency harmonics of both rectifiers working at $n_{m}=450 \mathrm{rpm}$ and $P$ $=2 \mathrm{~kW}$, corresponding to the waveforms of Fig. 16. A very important reduction of the most important harmonics $\left(5^{\text {th }}, 7^{\text {th }}, 11^{\text {th }}\right.$ and $\left.13^{\text {th }}\right)$ is observed, achieved by the proposed DCM rectifier. 


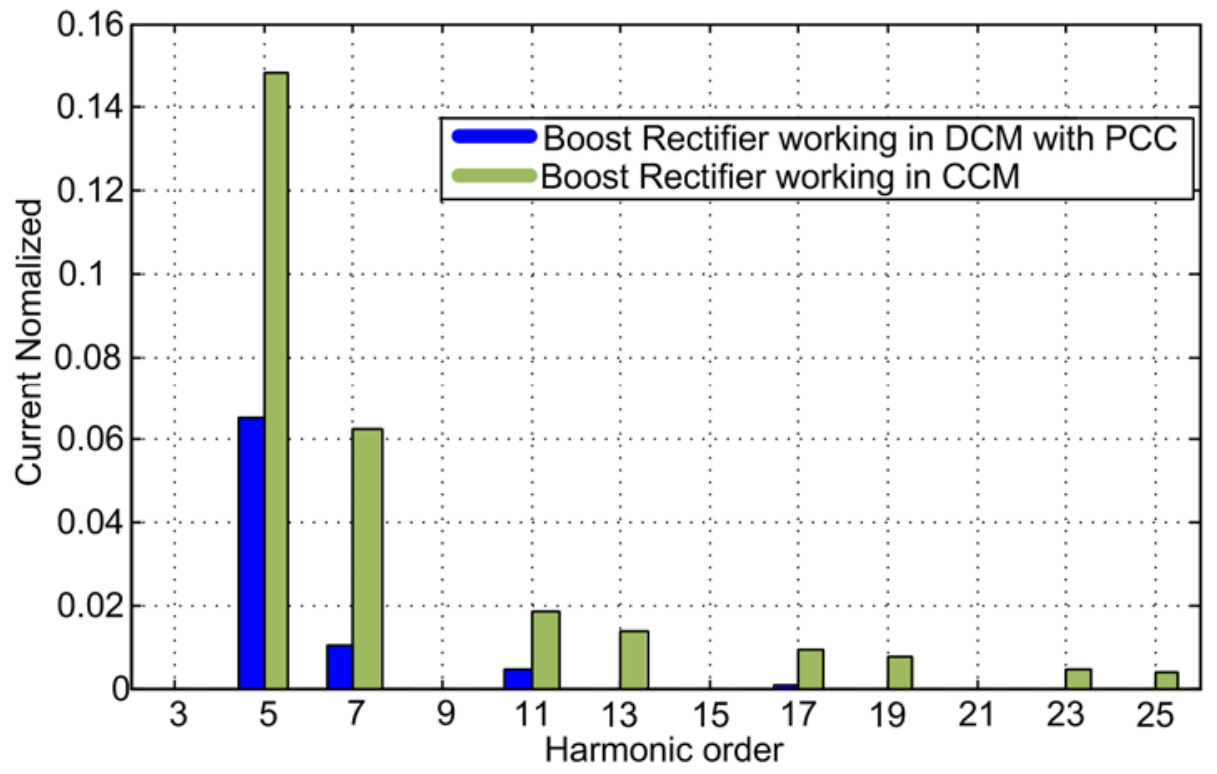

Fig. 17. Harmonics of the PMSG phase current provided by a Boost rectifier working in CCM vs. DCM with input filter: $n_{m}=450 \mathrm{rpm}, P=\mathbf{2} \mathrm{kW}$

Fig. 18 shows the comparative behavior of the $T H D_{i}$ and the $P F$ seen by the generator with both rectifiers. The variations of the generator voltage and frequency as a function of the generator speed in $\mathrm{rpm}$ have been considered. The maximum power available from the generator is also shown in the whole speed range (blue line). It is observed that both the $T H D_{i}$ and the $P F$ improve significantly in the whole speed range when the Boost Rectifier operates in DCM with input filter. The boost rectifier in CCM has a $T H D_{i}$ ranging from $6 \%$ to $22 \%$, whereas the proposed DCM rectifier has a $T H D_{i}$ ranging from $1 \%$ to $15 \%$. The reduction of $T H D_{i}$ achieved by the proposed rectifier reduces both the torque vibrations (see also Fig. $16 \mathrm{~b}$ ) and the overheating in the PMSG, extending its life cycle.

Regarding the PF improvement, the PF ranges from 0.27 to 0.74 in the conventional CCM boost rectifier, whereas a PF between 0.8 and 0.98 is observed in the proposed rectifier. Note that the increase of the energy extracted from the wind is very remarkable in the low power-low speed range, because the PF is raised from 0.27 (conventional rectifier) to 0.8 (proposed rectifier). In this low speed range the PMSG may operate an important part of the time. 



Fig. 18. The comparative behavior of the $T H D_{i}$ and the PF seen by the PMSG with both boost rectifiers.

In order to check the stability and dynamics of the adjusted peak current mode control, the response of the current drawn from the PMSG to steps in the control voltage, $V_{C}$, has been simulated. The value of $V_{C}$ is proportional to the desired electrical torque that will be applied to the PMSG. Fig. 19 shows the response of the current in one of the generator phases to a step of the control voltage from $1.222 \mathrm{~V}$ to $0.8 \mathrm{~V}$ at a constant PMSG speed of $450 \mathrm{rpm}$. The power obtained from the PMSG and the applied torque are depicted in the same figure. It is observed that the current loop is stable to both variations. The response time is much smaller than a period of the PMSG current. It can be concluded that the proposed peak current mode control is suitable as torque (current) controller of the PMSG in spite of the presence of an input filter, which might degrade the stability if a rigorous dynamic study of the PCC loop hadn't been performed. 



Fig. 19. Response of the current in one of the generator phases to a step of the control voltage, $V_{C}$, from $1.222 \mathrm{~V}$ to $0.8 \mathrm{~V}$ at a constant PMSG speed of $450 \mathrm{rpm}$.

\section{Conclusion}

In this paper it has been presented the design and analysis of a Three Phase Boost Rectifier with input filter applied to WECS based on Permanent Magnet Synchronous Generators. The maximum inductor value that allows working in DCM has been calculated considering all the elements of the system. The study of peak current mode control of the rectifier output current shows a high power factor of the system, and a low Total Harmonic Distortion of the generator output current. It has been shown that the adjustment of the stabilization ramp slope, $S_{e}$, of the peak current mode control is critical, because the input filter modifies the transfer function of the duty cycle to the inductor current. The proposed topology provides a $T H D_{i}$ ranging from $1 \%$ to $15 \%$ and a $P F$ ranging from 0.8 to 0.98 . The same rectifier working in CCM would provide a $T H D_{i}$ from $6 \%$ to $22 \%$ and a $P F$ from 0.27 to 0.74 .

The achieved reduction of the $T H D_{i}$ implies a decrease of the torque ripple from 3 to 1 , approximately, as well as lower rms currents drawn from the PMSG. The consequences are the reduction of both the mechanical (torque vibrations) and electrical (ohmic losses in the windings) stress in the generator, leading to the extension of its life cycle.

The increase of the energy extracted from the wind is very remarkable in the low power-low speed range, where the PF is raised from 0.27 (conventional rectifier) to 0.8 (proposed rectifier). It is worth pointing out the simplicity and low price of the proposed peak current 
mode controller, which can be implemented with any commercial PWM current control integrated circuit.

Finally, it is concluded from the dynamic simulations that the proposed peak current mode control is suitable as torque (current) control of the PMSG in spite of the presence of an input filter, so that the technique is compatible with both speed and torque control structures, which would provide the control voltage to the PCC current loop.

\section{Acknowledgements}

This work was supported by the Spanish Ministry of Science and Innovation under Grants ENE2006-15521-C03-02 and ENE2009-13998-C02-02. The first author thanks the support of the Instituto Politécnico Nacional (IPN) and of the Comisión de Operación y Fomento de Actividades Académicas (COFAA) to finance his stay at the Universidad Politécnica de Valencia (UPV).

\section{References}

[1] Thomas Ackermann, "Wind Power in Power Systems", England, Wiley, 2005.

[2] $\mathrm{H}$. Li and Z. Chen, "Overview of different wind generator systems and their comparisons", IET Renewable Power Generation, Vol. 2, No. 2, pp. 123-138, June 2008.

[3] Fawzi A.L. Jowder, "Wind power analysis and site matching of wind turbine generators in Kingdom of Bahrain", Applied Energy 86 (4), pp. 538-545, April 2009.

[4] Patrick J. Luickx, Erik D. Delarue, William D. D'haeseleer, "Considerations on the backup of wind power: Operational backup", Applied Energy 85 (9), pp. 787-799, September 2008

[5] Brian Snyder, Mark J. Kaiser, "A comparison of offshore wind power development in Europe and the U.S.: Patterns and drivers of development", Applied Energy 86 (10), pp. 1845-1856, October 2009.

[6] Hannes Weigt, "Germany's wind energy: The potential for fossil capacity replacement and cost saving", Applied Energy 86 (10), pp. 1857-1863, October 2009.

[7] R. Ahshan, M.T. Iqbal, George K.I. Mann, "Controller for a small induction-generator based windturbine", Applied Energy 85 (4), pp. 218-227, April 2008.

[8] Jamal A. Baroudi, Venkata Dinavahi, Andrew M. Knight, "A review of power converter topologies for wind generators" Renewable Energy 32, pp. 2369-2385, 2007.

[9] M. Arifujjaman, M. T. Iqbal and J. E. Quaicoe, "Energy capture by a small wind-energy conversion system". Applied Energy 85 (1), pp. 41-51, 2008

[10] Ali M. Eltamaly, "Harmonics reduction of three-phase boost rectifier by modulating duty ratio", Electric Power Systems Research 77, pp. 1425-1431, 2007.

[11] J. Tsai, K. Tan, "H APF harmonic mitigation technique for PMSG wind energy conversion system", Universities Power Engineering Conference, AUPEC 2007, Australasian, Dec. 2007.

[12] F.S. dos Reis, J.A.V. Ale, F.D. Adegas, R. Tonkoski, S. Slan, K. Tan, "Active Shunt Filter for Harmonic Mitigation in Wind Turbines Generators", 37th IEEE Power Electronics Specialists Conference, PESC '06, 2007.

[13] M. Arifujjaman, M. T. Iqbal and J. E. Quaicoe, "Reliability analysis of grid connected small wind turbine power electronics". Applied Energy 86 (9), pp. 1617-1623, 2009.

[14] Y. Jang, M. M. Jovanovic, "A New Input-Voltage Feedforward Harmonic-Injection Technique Nonlinear Gain Control for Single-Switch, Three-Phase, DCM Boost Rectifiers" IEEE Trans. on Power Electronics, vol. 20, no. 1, pp. 268-277, March 2000.

[15] P. Barbosa, F. Canales, J. C. Crebier, F.C. Lee, "Interleaved Three-Phase Boost Rectifiers Operated in the Discontinuous Conduction Mode: Analysis, Design Considerations and Experimentation" IEEE Trans. on Power Electronics, vol. 16, no. 5, pp. 724-734, September 2001.

[16] S.M. Bashi, N. Mariun, S.B. Noor and H.S. Athab, "Three-phase Single Switch Power Factor Correction Circuit with Harmonic Reduction”, Journal of Applied Sciences 5 (1): pp. 80-84, 2005. 
[17] R. Ghosh, G. Narayanan, "A Single-Phase Boost Rectifier System for Wide Range of Load Variations", IEEE Transactions on Power Electronics, Vol. 22, No. 2, pp. 470-479, March 2007

[18] A. Mirecki, X. Roboam, F. Richardeau, "Architecture Complexity and Energy Efficiency of Small Wind Turbines", IEEE Transactions on Industrial Electronics, Vol. 54, No. 1, pp. 660-670, February 2007

[19] Robert W. Erickson, Dragan Maksimovic, Fundamentals of Power Electronics, USA, Kluwer Academic Publishers, 2001.

[20] V. Vorperian, "Simplified analysis of PWM converters using model of PWM switch I and II" IEEE Trans. on Aerospace and Electronic Systems, vol. 26, no. 3, pp. 490-505, may 1990.

[21] R. B. Ridley, "A new, continuous-time model for current-mode control [power convertors]", IEEE Trans. on Power Electronics, vol. 6, no. 2, pp. 271-280, April 1991.

[22] PSIM 7.0 User's Guide (2006), Powersim Inc., March 2006. 